\title{
Extracellular Vesicles as a New Promising Therapy in HIV Infection
}

\author{
Maria A. Navarrete-Muñoz ${ }^{1,2,3}$, Carlos Llorens $^{3}$, José M. Benito ${ }^{1,2^{\star *}}$ and Norma Rallón ${ }^{1,2^{\star t}}$ \\ ${ }^{1}$ HIV and Viral Hepatitis Research Laboratory, Instituto de Investigación Sanitaria Fundación Jiménez Díaz (IIS-FJD), \\ Universidad Autónoma de Madrid (UAM), Madrid, Spain, ${ }^{2}$ Hospital Universitario Rey Juan Carlos, Móstoles, Spain, \\ ${ }^{3}$ Biotechvana, Madrid Scientific Park Foundation, Madrid, Spain
}

\section{OPEN ACCESS}

Edited by:

Denise L. Doolan,

James Cook University, Australia

Reviewed by:

Matthias Clauss,

Indiana University Bloomington,

United States

*Correspondence:

José M. Benito

jbenito1@hotmail.com;

jose.benito@fjd.es

Norma Rallón

normaibon@yahoo.com;

norma.rallon@fjd.es

${ }^{+}$ORCID

José M. Benito

orcid.org/0000-0002-7172-049X

Norma Rallón

orcid.org/0000-0002-4643-247X

Specialty section:

This article was submitted to Vaccines and Molecular Therapeutics,

a section of the journal

Frontiers in Immunology

Received: 08 November 2021

Accepted: 15 December 2021

Published: 04 January 2022

Citation:

Navarrete-Muñoz MA, Llorens C,

Benito JM and Rallón N (2022)

Extracellular Vesicles as a New

Promising Therapy in HIV Infection.

Front. Immunol. 12:811471.

doi: 10.3389/fimmu.2021.811471
Combination antiretroviral therapy (cART) effectively blocks HIV replication but cannot completely eliminate HIV from the body mainly due to establishment of a viral reservoir. To date, clinical strategies designed to replace CART for life and alternatively to eliminate the HIV reservoir have failed. The reduced expression of viral antigens in the latently infected cells is one of the main reasons behind the failure of the strategies to purge the HIV reservoir. This situation has forced the scientific community to search alternative therapeutic strategies to control HIV infection. In this regard, recent findings have pointed out extracellular vesicles as therapeutic agents with enormous potential to control HIV infection. This review focuses on their role as pro-viral and anti-viral factors, as well as their potential therapeutic applications.

Keywords: intercellular communication, extracellular vesicles (EVs), HIV infection, immunopathogenesis, clinical application, EVs as therapeutic agents for HIV, EVs as latency reversal agents

\section{INTRODUCTION}

Global HIV statistics indicate that around 37.7 million people are living with HIV infection with 1.5 million people newly infected in 2020 (1). Combination antiretroviral therapy (cART) has successfully decreased the associated mortality and consequently it has improved life expectancy (2). The cART can effectively block viral replication reducing plasma viremia to undetectable levels (3). However, cART is not able to completely restore immunological functions (4) and to reduce immune hyperactivation and persistent chronic systemic inflammation caused by HIV (5) which is associated with higher risk of developing cancer, as well as cardiovascular, metabolic, and bone disorders (6-9).

In addition, the cumulative toxicity of cART regimens remains a concern in people living with HIV (10-13). This toxicity added to the obligation of lifelong treatment prompted the research on different strategies with the aim to replace cART for life. These strategies include: a) the reduction of number of target cells available for the virus by CCR5-deficient bone marrow transplant (14-16); b) cART administration very early after primary (17) or acute (18) HIV infection to achieve posttreatment control after drug interruption; c) immunotherapies to delay HIV reactivation by blocking reactivation events (19); d) therapeutic HIV vaccines generated to boost the magnitude, breadth and functionality of HIV-specific immune response $(20,21)$. However, these strategies have not achieved the expected success, even for the strategy aimed at reducing available CCR5-cells, which is not feasible for the whole $\mathrm{HIV}^{+}$population, it was only successful in only two exceptional patients $(14,15)$. Thus, it is necessary to focus research on alternative solutions. In this regard, EVs 
and their observed role in HIV restriction at multiples levels (22-29) lead to consider the potential application of these vesicles in the treatment of HIV infection in order to replace cART treatment.

Moreover, cART cannot completely eliminate the virus from the body, and viral load rapidly re-emergences after 2-8 weeks of cART interruption $(30,31)$. Establishment of a viral reservoir, very early after acute infection, has been proposed as the main reason for viral rebound and consequently as the main obstacle for HIV eradication. Different types of HIV reservoir have been described. First, the cellular HIV reservoir, formed by specific cells, in a latent state, with HIV-DNA integrated into their genome (32), being the virus invisible to the action of the immune system and of the cART. Second, the anatomical reservoirs, which are sites where the cART and/or the effector cells of the immune system cannot access allowing HIV replication for long periods of time (33).

Several therapeutic strategies specifically designed to eliminate HIV reservoir have been developed with limited success to date. Within them, the most widely explored strategy is the shock and kill approach (34). The goal of this strategy is to eliminate the HIV reservoir, either by cART or immune system, after reactivating it by using latency reversal agents -LRAs-. Despite of the promising results, this strategy has not achieved the expected results $(35,36)$. The "shock" phase fails to completely reactivate the reservoir, with only $<1 \%$ of proviruses being reactivated after maximum in vitro activation (37). Moreover, this strategy does not discriminate between replication-competent and defective proviruses, and the response to LRAs is widely variable among patients due to the heterogeneous nature of the cellular and anatomical reservoirs and other features such as virus-integration sites and patientspecific aspects (38). Therefore, the search for strategies that can effectively target the HIV reservoir remain open. In this sense, recent findings have pointed out extracellular vesicles (EVs) as potential therapeutic tools to attack HIV infection given their pivotal role in mediating important cell-to-cell communication mechanisms (39).

In this Review, we focus on the understanding how extracellular vesicles mediate intercellular communication in HIV infection, its role as pro-viral and anti-viral factors and its tremendous potential as therapeutic agents to control HIV infection (blocking HIV infectivity and/or reactivating the HIV reservoir).

\section{INTERCELLULAR COMMUNICATION MEDIATED BY EVs IN HIV INFECTION}

Exosomes are membranous EVs of around 40-100 nm, released by many types of cells into the extracellular environment, found in several biological fluids such as blood, urine, semen and breast milk. Most studies use the term "exosomes" to refer to circulating vesicles. However, circulating vesicles are composed of exosomes and microvesicles, and the isolation techniques used do not allow a complete discrimination between them (40). Tetraspanins such as CD63, CD9, and CD81 are normally used as EVs-specific markers. Other proteins, such as Alix and Tsg101 are involved in their biogenesis. It is important to note that HIV virions and exosomes/microvesicles share many features including biophysical and molecular properties, biogenesis and uptake mechanisms. Indeed, Alix and Tsg101 proteins play important roles in the budding of HIV from the host cell (41).

Similarities found between HIV virions and exosomes/ microvesicles lead to the so-called "Trojan Exosome Hypothesis", first proposed by Gould et al. (42). According to this hypothesis, HIV and other retroviruses will take advantage of the host cell exosomal biogenesis machinery for their own benefit. This hypothesis has implications for the virus-host interactions at several levels. The most obvious implication is that the hijacking by HIV of exosomal biogenesis machinery will lead to alternative ways for virus spreading and infection of new target cells, different from the classic direct budding from the plasma membrane (42). Also, the similarity between exosomes and viral biogenesis implies that several viral products can be incorporated into exosomes as several studies have reported (43-48). Full-length unspliced HIV RNA (43), several miRNAs such as the trans-activating response (TAR) element (44-46) and different viral proteins $(47,48)$ have all been found carried by exosomes of different origin. This ability of HIV to package its own products into exosomes has relevant implications not only for viral spreading but also for viral pathogenesis. In this regard, several studies point to Nef protein as especially relevant in different EVs-mediated mechanisms of viral pathogenesis. First, Nef can promote HIV infection by reducing the expression of CD4 in exosomes and thus neutralizing the ability of CD4bearing exosomas to act as decoys (49). Second, HIV-infected macrophages can transfer Nef to B cells altering the virus-specific Ig-class switching in lymphoid follicles (50). Virus-specific T-cell responses are also affected by Nef through its modulating effect on both TCR-signalling and cytoskeleton reorganization in $\mathrm{T}$ cells. This effect of Nef is dependent on the hijacking of endosomal traffic of protein tyrosine kinase Lck (essential for TCR signaling) and the GTPase Racl (essential for cytoskeleton reorganization) (51). Lastly, Nef carried by exosomes has also been involved in promoting chronic inflammation through its effect on lipid rafts formation (reducing the activation of the GTPase Cdc42 and increasing the activation of NLRP3 inflammasome) (52).

In contrast, EVs may contribute to an anti-viral response by delivering HIV restriction factors to nearby cells or by presenting viral antigens $(53,54)$. Moreover, cell-to-cell communication by EVs could play an important role in the reactivation of the latent HIV (55-60), something of utmost relevance in the search for strategies aimed at eliminating the reservoir.

\section{PRO-VIRAL EFFECTS OF EVs IN HIV INFECTION}

As has been mentioned, EVs can promote HIV infection (Figure 1). HIV-RNA (43), and the HIV proteins Nef (61), 


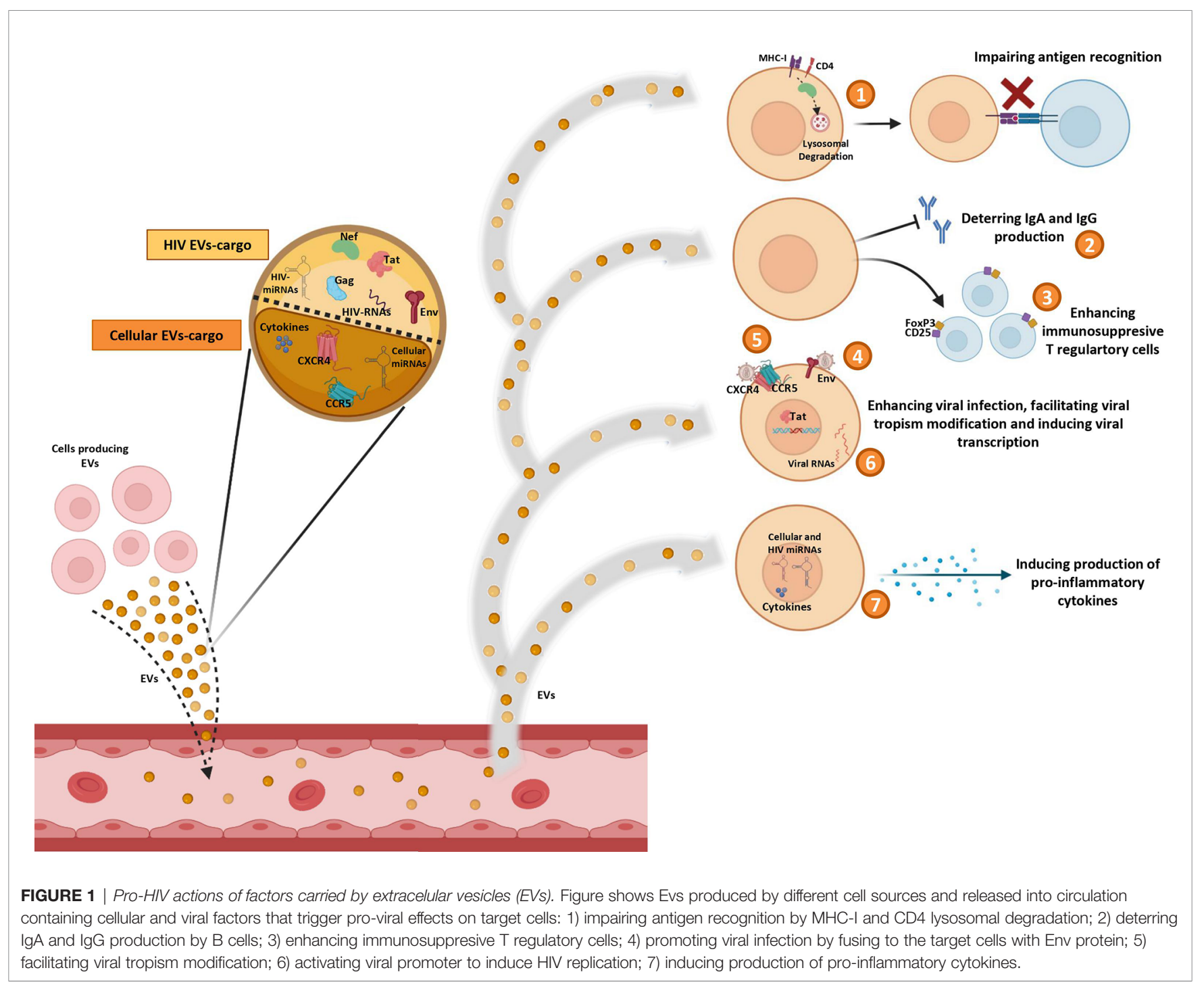

Gag, Tat (62), and Env (63) have been observed into EVs from cell culture supernatants. Nef protein can interact with cellular trafficking pathways and induce lysosomal degradation of MHCI $(64,65)$ and $\operatorname{CD} 4(64,66)$, disrupting the viral antigen recognition by immune system (67). Moreover, an inhibitory effect of Nef on the adaptive immune response, by deterring the IgA and IgG production in B lymphocytes, has also been described in EVs derived from macrophages of HIV-infected subjects (50). Tat protein acts activating viral promoter to induce HIV replication (62). Gag (62) and Env (63) proteins participate in infection enhancement. EVs released by HIV-infected cells contain Env protein gp120 suggesting that this protein secreted in EVs may promote the virus to attach and fuse to the target cells and facilitate HIV infection (63).

Some HIV-miRNAs have been also observed in EVs from serum of HIV-infected patients and from infected cells culture (44-46). These miRNAs are involved in cytokine production (44-46) and in apoptosis downregulation (44). In general, it seems that EVs can impair the immune response by enhancing immunosuppressive Foxp $3^{+} \mathrm{CD} 4^{+} \mathrm{CD} 25^{+} \mathrm{T}$ regulatory cells (68). Furthermore, EVs can act as inducers of the inflammatory state that contributes to HIV disease pathogenesis. Different studies have reported several molecules associated to development of inflammation into EVs, such as: TNF $\alpha(69,70)$, IFNg (71), IL12p40, sIL-6R, sTNF-RI, GRO (69), MCP-1, RANTES (72), IL$1 \alpha(70,71)$, CXCL10 (70), viral Nef protein (that triggers TNF- $\alpha$ release) (73), viral miRNAs $(45,46)$, and cellular miRNAs (miR10a-5p, miR-21-5p, miR-27b-3p, miR-122-5p, miR-146a-5p, miR-423-5p) (74). In addition, EVs derived from plasma of HIV subjects increase activation of monocytes/macrophages eliciting the production of inflammatory cytokines (IL-6, IL1- $\beta$ and TNF- $\alpha$ ) by these cells (75).

Interestingly, in vitro studies with EVs derived from cell lines culture supernatants (76) and from human peripheral blood mononuclear cells (PBMCs) (76) or platelets (77) of healthy donors, have revealed that virus can be able to use EVs to transfer CCR5 and CXCR4 HIV entry co-receptors to cells in order to facilitate the modification of the viral tropism increasing the 
number of susceptible target cells $(76,77)$. However, this ability of EVs to transfer HIV coreceptors between cells could be exploited to combat HIV by engineering exosomes carrying defective correceptors with the aim to prevent HIV transmission, as is the case for the natural delta32-deleted version of host CCR5 (78).

\section{ANTI-VIRAL EFFECTS OF EVs IN HIV INFECTION}

Several anti-HIV effects of EVs have been described, such as the presence of MHC-II molecules as part of EVs cargo, a fact that reveals the potential ability of these vesicles to present viral antigens and induce $\mathrm{T}$ cells response (54). Tumne et al. revealed that EVs secreted by CD8 + T cells display a potent noncytotoxic antiretroviral activity that specifically inhibits HIV transcription (79).

Some studies have assessed the capacity of EVs to transfer known restriction factors that can inhibit HIV infection in target cells (Figure 2). One of these factors is APOBEC3G (A3G human cytidine deaminase that can cause hypermutation of the viral genome at the retrotranscription step) that has been found into EVs that potently restrict replication of HIV in recipient cells under in vitro conditions (80). Moreover, A3G and Tetherin (an interferon-induced protein whose expression blocks the

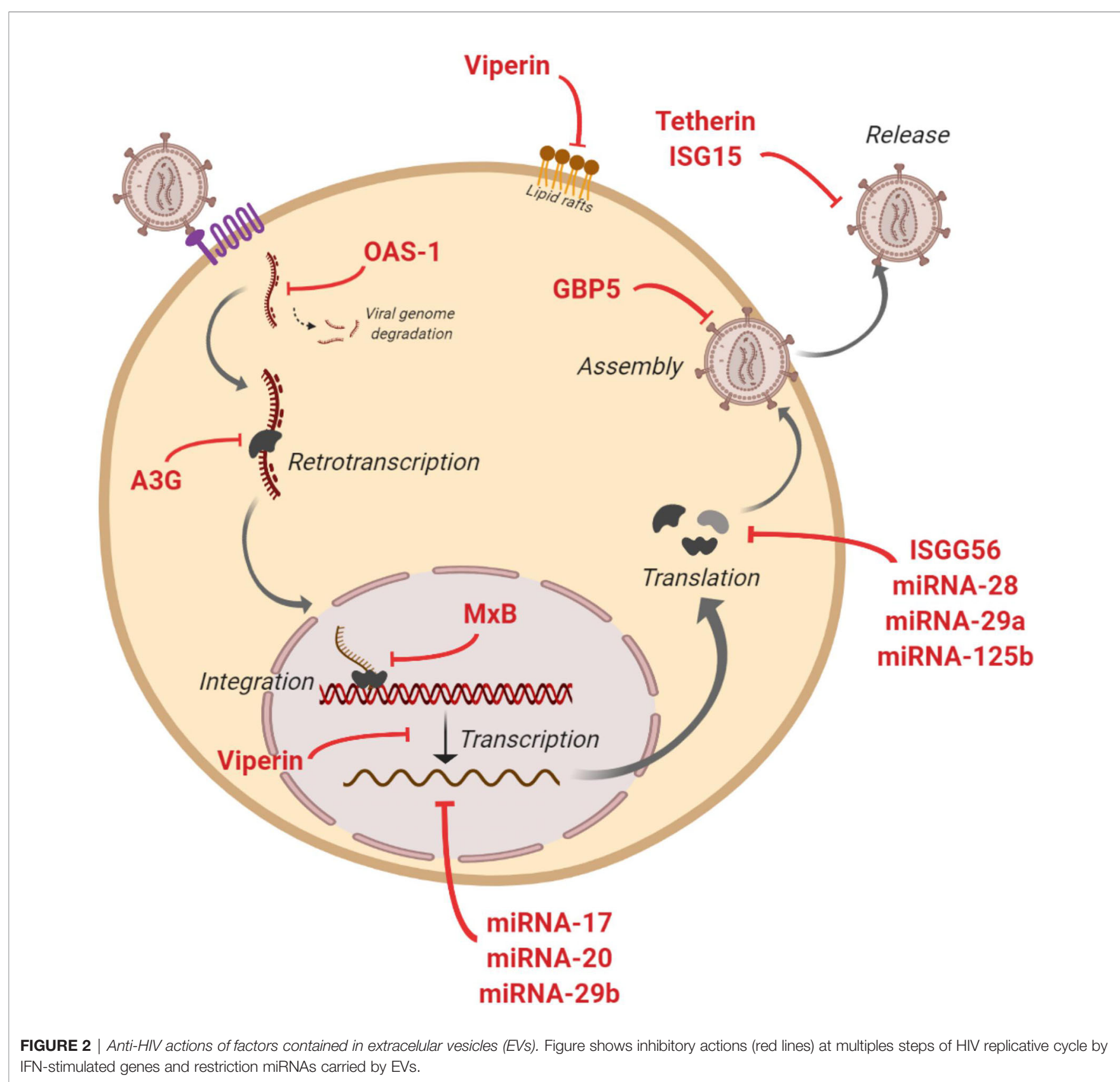


release of HIV), have also been found into EVs derived from human semen (22). At level of mRNA of cellular restriction factors, Tetherin and A3G expression could be induced by EVs. An in vitro study showed that EVs from intestinal epithelial cells culture transport antiviral factors at mRNA and protein levels to macrophages, increasing the expression of antiviral IFNstimulated genes (ISGs) and cellular HIV restriction factors, including Tetherin and $\mathrm{A} 3 \mathrm{G}$, that restricts HIV replication in macrophages (23).

The presence of IFN-stimulated genes ISG15, ISG56, MxB, OAS-1, GBP5, and Viperin with anti-HIV activity has also been reported in EVs $(23,24)$. These genes code for proteins with diverse functions aimed at blocking HIV: ISG15 protein inhibits virions release; ISG56 restricts viral protein translation; $\mathrm{MxB}$ reduces viral DNA integration; OAS-1 activates RNAsa-L to degrade viral genome; GBP5 interferes in the Env protein incorporation to generated virions; and Viperin disturbs lipid rafts and impairs viral replication (Figure 2). Moreover, different miRNAs with a protective action against HIV have been found in EVs such as miRNA-17, miRNA-20, miRNA-28, miRNA-29a, miRNA29b and miRNA-125b (23). These anti-HIV miRNAs could regulate HIV expression by directly targeting the virus or by an indirect effect targeting cellular transcription factors. Thus, HIV virus is inhibited at multiple steps of its viral cycle (Figure 2). A very recent study has shown that EVs released from human TLR3-activated cervical epithelial cells contain antiviral factors such as multiple IFN-stimulated genes and $\mathrm{HIV}$ restriction miRNAs that were able to restrict HIV replication in macrophages in culture. These results suggest that this antiviral mechanism could participate in the innate immunity against HIV infection, and thus a EVs-based delivery system could be considered as a preventive strategy to protect the female reproductive tract against HIV sexual transmission (25).

Concerning the effect of EVs from body fluids, several studies suggest the presence of inhibitory components in semen-derived EVs that can mitigate HIV replication and sexual transmission. EVs derived from semen of healthy donors contain mRNA of Tetherin and A3G that could inhibit HIV infection of various cell types by potentially impairing reverse transcriptase activity (22). Also, these Evs blocked the spread of HIV from vaginal epithelial cells to other cells by restricting cell-to-cell transmission (26). HIV post-entry inhibitory effect of EVs derived from semen of healthy subjects has been proposed by Welch JL et al., in an in vitro study in which these EVs blocked HIV proviral transcription by repressing NF-k $\beta$, RNA polymerase II, and Tat recruitment to the LTR region, and thus blocking transcription, initiation, and elongation (27). A recent study enrolling HIV-negative, HIV-infected cART-naïve and HIVinfected cART-treated participants observed that EVs derived from semen inhibited HIV replication in vitro independently of donor HIV-infection status (28). In addition, EVs derived from semen of healthy subjects downregulated HIV-induced proinflammatory cytokine production while preserved lymphocyte activation state (81).

EVs from other body fluids have also shown anti-HIV effects. EVs isolated from vaginal fluid could block HIV in vitro at post- entry steps, most likely by halving the reverse transcription and the integration processes (29). In EVs derived from breast milk of healthy donors has been shown an in vitro protective role. These EVs may bind to monocyte-derived dendritic cells via DC-SIGN, a common receptor used by HIV, and consequently, inhibit infection and viral transfer to CD4+ T cells (82).

All this evidence the potential application of these extracellular vesicles in the treatment of HIV infection as a novel and alternative solution to cART for life. EVs can be used as therapeutical agents either by taking advantage of their own natural cargo or by devising ways to engineering their content with different therapeutic agents ranging from antiHIV drugs to immunomodulating factors. Since EVs function as natural transporters of different molecules between cells and play a pivotal role in intercellular communication, it is expected that they should be the ideal way of delivering different biomolecules to the desired target cells (83). Compared to more traditional approaches of drug delivering including liposome-based or cell-based therapy, EVs offer several advantages such as easier manipulation, long half-life, and higher biocompatibility (84). The feasibility to use EVs as delivery systems has been demonstrated in several studies reporting the use of exosomes as carriers of biomolecules to different types of cells $(85,86)$. Moreover, recent studies have suggested the potential of EVs as drug delivery systems for treatment of human viral diseases $(87,88)$. In the setting of HIV infection, the therapeutic potential of EVs is supported by clinical data emerging from other human diseases, especially from the field of cancer (89). Although EVs-based clinical trials for treating HIV have not yet been developed, different approaches have been proposed including the loading of EVs with small molecules with anti-HIV activity (84) and with HIV proteins to generate anti-HIV immune responses $(90,91)$.

\section{ROLE OF EVs IN HIV RESERVOIR REACTIVATION}

To date, none of clinical trials using LRAs have reached a significant and persistent reduction of the HIV reservoir. Therefore, an alternative strategy is necessary to efficiently reactivate the transcription of latent $\mathrm{HIV}$ as a necessary step to purge the reservoir by the combined action of cART, blocking the released virus, and of the host immune system, destroying productively infected cells (Figure 3A). Several studies have found that EVs can reactivate latent $\mathrm{HIV}$ infection through different mechanisms (55-60) (Figure 3B) as outlined below:

i) Viral transcripts are increased in HIV infected cells when these cells are exposed to purified EVs derived from uninfected cells culture (58). Barclay et al, showed that EVs from uninfected cells culture increased the amount of RNA polymerase II loading onto the HIV promoter, and also increased Cdk9 binding to the transcriptional complex in order to enhance RNA polymerase elongation. In a more recent study, it has been observed that EVs from uninfected cells culture contained activated c-Src (protooncogene tyrosine-protein kinase Src) that can trigger the PI3K/ 

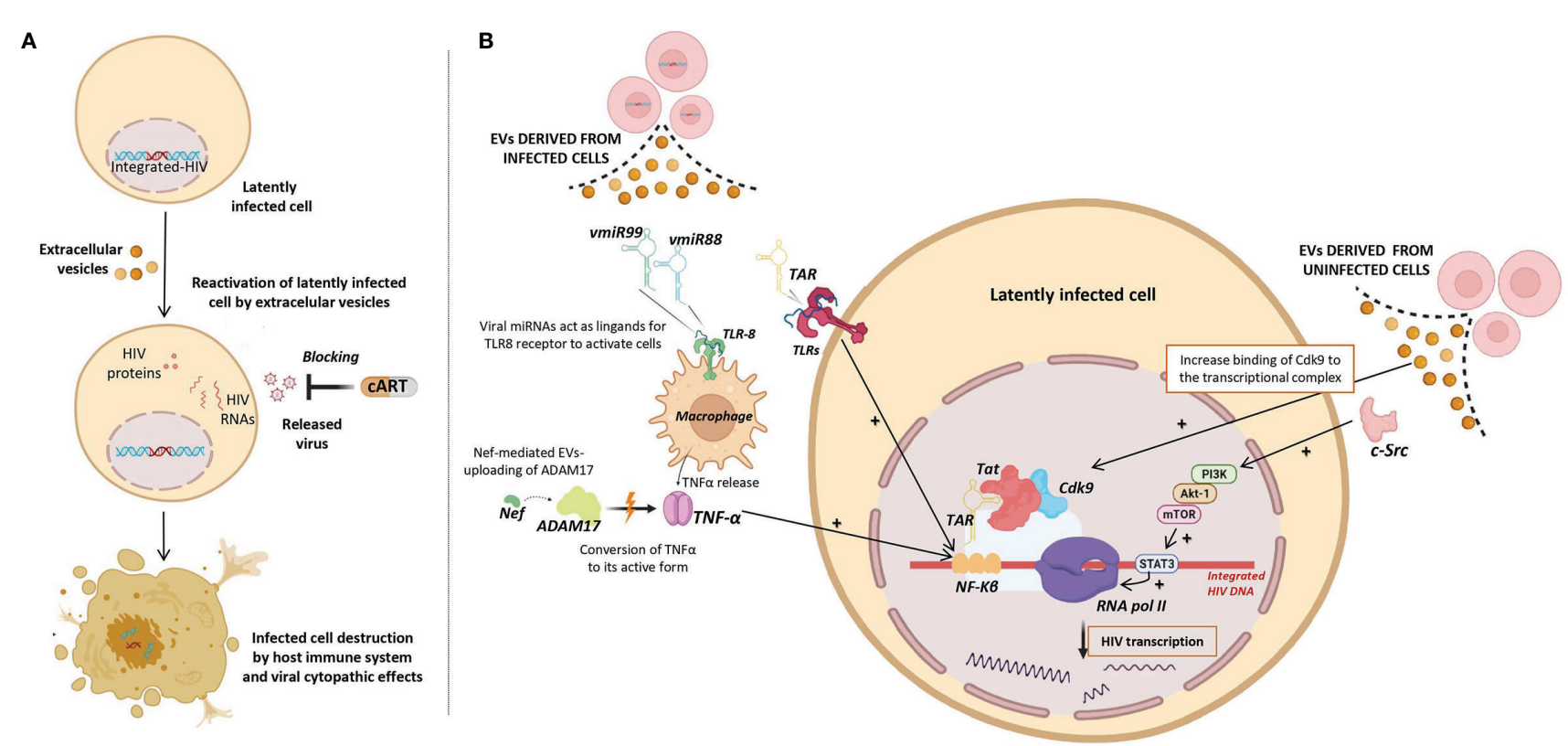

FIGURE 3 | Role of Extracellular vesicles in HIV reservoir reactivation (EVS). (A) Potential use of EVs as latency reversing agents (LRAs) to reactivate latently HIV infected cells. Reactivated infected cells produce viral antigens and can be destroyed either by viral cytopathic effects and/or by the host immune system, while released virus can be blocked by combination antiretroviral therapy (cART). (B) Different viral factors carried by EVs released from infected cells (left) and EVs released from uninfected cells (right) that could be involved in the induction of HIV transcription and consequently reactivation of HIV latency. Different molecular pathways involved in induction of HIV transcription are shown. Up-regulating actions are represented by black positive arrows.

AKT-1/mTOR signaling cascade, resulting in the activation of the transcription inducer STAT3, promoting the loading of RNA polymerase II onto the HIV promoter and allowing the reactivation of latent HIV (92). As consequence, larger amounts of viral transcripts were available to be packaged into new EVs and to be exported to uninfected cells.

ii) Tat, a known transactivator of viral transcription, has been detected in EVs isolated from urine of HIV infected patients (93). Tang et al. studied the role of EVs-delivered Tat in the reactivation of viral replication in latently-infected cells (55). For this purpose, the authors engineered human cellular EVs expressing activated Tat protein and they found that EVsdelivered Tat increased the potency of a selected LRA by over 30-fold, measured as change in HIV mRNA expression.

iii) EVs derived from infected cells have also been shown to contain HIV miRNAs that regulate viral and host gene expression (44-46). The most frequent miRNA found in serum EVs of HIVinfected patients is the trans-activation response element (TAR), which down-regulates apoptosis and enhances susceptibility to infection (44). A direct role of TAR in cytokine gene expression has been described by Sampey et al. (46), that observed increased levels of IL- 6 and TNF- $\beta$ in co-cultures of macrophages with EVs derived from HIV in vitro infected cells. They suggested that the underlying mechanism by which TAR increases the expression of these cytokines involves the activation of the NF-k $\beta$ pathway through the binding of TAR to the TLRs and PKR kinase. Interestingly, NF-k $\beta$ regulates the transcriptional activity of the long terminal repeat (LTR) region and therefore, enhances transcription of the HIV genome (94). iv) Other viral miRNAs such as vmiR88 and vmiR99 have also been observed packaged into EVs derived from serum of HIV-infected patients (45). Bernard et al. found that vmiR88 and vmiR99 could act as ligands for TLR8 signaling that promotes macrophage TNF $\alpha$ release, a cytokine with a pivotal role in the chronic immune activation. TNF $\alpha$ is a pleiotropic protein with several roles in HIV pathogenesis, among them the induction of the nuclear factors binding to the NF-k $\beta$ in the LTR, resulting in an increase of HIV RNA expression (95). Interestingly, immature TNF $\alpha$ is converted into its active form by ADAM17, a disintegrin and metalloprotease present in EVs derived from in vitro $\mathrm{HIV}$ infected cells culture, with a relevant function in the HIV replication in resting CD4+ T cells (60). The packaging of ADAM17 has been observed only in EVs that also contain viral Nef protein. Arenaccio et al. showed that Nef seems to induce the uploading of active ADAM17 in EVs, highlighting the importance of Nef in the mechanism of latent HIV reactivation (60). Reactivation of latent HIV was not observed when Nef was absent or defective (59). Similarly, HIV reactivation was abolished when an inhibitor of the pro-TNF $\alpha$ processing ADAM17 enzyme or neutralizing antibodies of TNF $\alpha$ were present (59).

All this highlight the relevant role of extracellular vesicles in the reactivation of the latent HIV and its potential application as an innovative and promising strategy aimed at eliminating the reservoir. Some of the studies mentioned above suggest that EVs could be engineered to carry different molecules to act as latency reversing agents. More specifically, the studies of Tan et al. (55), Arenaccio et al. (59) and Barclay et al. (92) clearly demonstrate in 
in vitro systems the ability of EVs to induce HIV transcription and thus reservoir reactivation. These studies are a proof of concept of the potential use of EVs in reservoir reactivation and further studies in the near future are warranted to test the feasibility of this approach in the in vivo situation.

\section{CONCLUSIONS AND FUTURE PERSPECTIVES}

The study of EVs in HIV pathogenesis is an emerging field with enormous therapeutic potential to achieve HIV remission. In the current scenario, EVs engineering is possible, with the aim of manipulating their cargo in order to deliver selected molecules to the target cells. Use of EVs for HIV therapeutic purposes may range from modulating immune response, through anti-HIV factors delivery to target cells, in order to block HIV infectivity and control infection, to activating the viral reservoir with the aim to its elimination by either viral cytopathic effects and/or by the host immune system. However, further in vivo studies are urgently needed to ascertain the role of EVs in HIV infection and its application at the clinical level.

\section{SEARCH STRATEGY AND SELECTION CRITERIA}

Relevant scientific literature was surveyed to review evidence and prepare the manuscript. We searched PubMed for English language papers published until October 2021. Search terms included: "HIV infection", "Exosomes and HIV", "Extracellular

\section{REFERENCES}

1. UNAIDS. Global Aids Update. Geneva, Switzerland : Joint United Nations Programme on HIV/AIDS (UNAIDS) (2020).

2. Mocroft A, Ledergerber B, Katlama C, Kirk O, Reiss P, d'Arminio Monforte A, et al. Decline in the AIDS and Death Rates in the EuroSIDA Study: An Observational Study. Lancet (2003) 362:22-9. doi: 10.1016/s0140-6736(03) 13802-0

3. Perelson AS, Essunger P, Cao Y, Vesanen M, Hurley A, Saksela K, et al. Decay Characteristics of HIV-1-Infected Compartments During Combination Therapy. Nature (1997) 387:188-91. doi: 10.1038/387188a0

4. Kelley CF, Kitchen CM, Hunt PW, Rodriguez B, Hecht FM, Kitahata M, et al. Incomplete Peripheral CD4 ${ }^{+}$Cell Count Restoration in Hiv-Infected Patients Receiving Long-Term Antiretroviral Treatment. Clin Infect Dis (2009) 48:787-94. doi: 10.1086/597093

5. Wada NI, Jacobson LP, Margolick JB, Crabb Breen E, Macatangay B, Penugonda S, et al. The Effect of HAART-Induced HIV Suppression on Circulating Markers of Inflammation and Immune Activation. AIDS (2015) 29(4):463-71. doi: 10.1097/QAD.0000000000000545

6. Nasi M, De Biasi S, Gibellini L, Bianchini E, Pecorini S, Bacca V, et al. Ageing and Inflammation in Patients With HIV Infection. Clin Exp Immunol (2017) 187(1):44-52. doi: 10.1111/cei.12814

7. Funderburg NT, Mehta NN. Lipid Abnormalities and Inflammation in HIV Infection. Curr HIV/AIDS Rep (2016) 13(4):218-25. doi: 10.1007/s11904-0160321-0

8. Vos AG, Idris NS, Barth RE, Klipstein-Grobusch K, Grobbee DE. ProInflammatory Markers in Relation to Cardiovascular Disease in HIV vesicles and HIV", "Intercellular communication in HIV infection", "Exosomes and HIV inhibition", "Extracellular vesicles and HIV inhibition", "Proviral effects of Extracellular vesicles in HIV infection", "Antiviral effects of Extracellular vesicles in HIV infection", "Toxicity ART and HIV", "Alternative strategy to ART HIV", "Strategies HIV functional cure", "HIV reservoir", "Exosomes and HIV reservoir", "Extracellular vesicles and HIV reservoir" and "Role of Extracellular vesicles in HIV reservoir reactivation" Authors screened abstracts for relevance and reviewed full-text articles deemed relevant to the topics address in the manuscript.

\section{AUTHOR CONTRIBUTIONS}

All authors have participated in the preparation of the manuscript with contributions to draft the manuscript or providing revisions to content. All authors reviewed and approved the final version of the manuscript.

\section{FUNDING}

This work has been partially funded by the Spanish Directorate General for Research and Technological Comunidad de Madrid fund [grant: IND2018/BMD9651] and the Spanish Carlos III Institute of Health-ISCIII and FEDER fund [grant: PI19/01237]. M-NM is a predoctoral student funded by grant IND2018/ BMD9651. NR is supported by the Miguel Servet program funded by the Spanish Health Institute Carlos III [grant: CPII19/00025].

Infection. A Systematic Review. PloS One (2016) 11(1):e0147484 doi: 10.1371/journal.pone.0147484

9. D’Abramo A, Zingaropoli MA, Oliva A, D'Agostino C, Moghazi SA, De Luca $\mathrm{G}$, et al. Higher Levels of Osteoprotegerin and Immune Activation/ Immunosenescence Markers Are Correlated With Concomitant Bone and Endovascular Damage in HIV-Suppressed Patients. PloS One (2016) 11(2): e0149601. doi: 10.1371/journal.pone.0149601

10. Borges ÁH, Hoy J, Florence E, Sedlacek D, Stellbrink HJ, Uzdaviniene V, et al. Antiretrovirals, Fractures, and Osteonecrosis in a Large International HIV Cohort. Clin Infect Dis (2017) 64(10):1413-21. doi: 10.1093/cid/cix167

11. Scherzer R, Estrella M, Li Y, Choi AI, Deeks SG, Grunfeld C, et al. Association of Tenofovir Exposure With Kidney Disease Risk in HIV Infection. AIDS (2012) 26(7):867-75. doi: 10.1097/QAD.0b013e328351f68f

12. Ma Q, Vaida F, Wong J, Sanders CA, Kao Y, Croteau D, et al. Long-Term Efavirenz Use Is Associated With Worse Neurocognitive Functioning in HIVInfected Patients. J Neurovirol (2016) 22(2):170-8. doi: 10.1007/s13365-015-0382-7

13. Friis-Møller N, Sabin CA, Weber R, d'Arminio Monforte A, El-Sadr WM, Reiss P, et al. Combination Antiretroviral Therapy and the Risk of Myocardial Infarction. N Engl J Med (2003) 349(21):1993-2003. doi: 10.1056/ NEJMoa030218

14. Hütter G, Nowak D, Mossner M, Ganepola S, Müssig A, Allers K, et al. LongTerm Control of HIV by CCR5 Delta32/Delta32 Stem-Cell Transplantation. N Engl J Med (2009) 360(7):692-8. doi: 10.1056/NEJMoa0802905

15. Gupta RK, Abdul-Jawad S, McCoy LE, Mok HP, Peppa D, Salgado M, et al. HIV-1 Remission Following CCR5 $32 / \Delta 32$ Haematopoietic Stem-Cell Transplantation. Nature (2019) 568(7751):244-8. doi: 10.1038/s41586-0191027-4 
16. Ding J, Liu Y, Lai Y. Knowledge From London and Berlin: Finding Threads to a Functional HIV Cure. Front Immunol (2021) 12:688747. doi: 10.3389/ fimmu.2021.688747

17. Sáez-Cirión A, Bacchus C, Hocqueloux L, Avettand-Fenoel V, Girault I, Lecuroux C, et al. Post-Treatment HIV-1 Controllers With a Long-Term Virological Remission After the Interruption of Early Initiated Antiretroviral Therapy ANRS VISCONTI Study. PloS Pathog (2013) 9:e1003211. doi: 10.1371/journal.ppat.1003211

18. Kaufmann D, Lichterfeld M, Altfeld M, Addo MM, Johnston MN, Lee PK, et al. Limited Durability of Viral Control Following Treated Acute HIV Infection. PloS Med (2004) 1(2):e36. doi: 10.1371/journal.pmed.0010036

19. Barouch DH, Whitney JB, Moldt B, Klein F, Oliveira TY, Liu J, et al. Therapeutic Efficacy of Potent Neutralizing HIV-1-Specific Monoclonal Antibodies in SHIV-Infected Rhesus Monkeys. Nature (2014) 503:224-8. doi: $10.1038 /$ nature 12744

20. Mothe $B$, Climent N, Plana $M$, Rosàs $M$, Jiménez JL, Muñoz-Fernández MA, et al. Safety and Immunogenicity of a Modified Vaccinia Ankara-Based HIV-1 Vaccine (MVA-B) in HIV-1-Infected Patients Alone or in Combination With a Drug to Reactivate Latent HIV-1. J Antimicrob Chemother (2015) 70 (6):1833-42. doi: 10.1093/jac/dkv046

21. Hargrave A, Mustafa AS, Hanif A, Tunio JH, Hanif SNM. Current Status of HIV-1 Vaccines. Vaccines (Basel) (2021) 9(9):1026. doi: 10.3390/ vaccines 9091026

22. Madison MN, Roller RJ, Okeoma CM. Human Semen Contains Exosomes With Potent Anti-HIV-1 Activity. Retrovirology (2014) 11:102. doi: 10.1186/ s12977-014-0102-z

23. Guo L, Xu XQ, Zhou L, Wang X, Li JL, Liu JB, et al. Human Intestinal Epithelial Cells Release Antiviral Factors That Inhibit HIV Infection of Macrophages. Front Immunol (2018) 9:247. doi: 10.3389/fimmu.2018.00247

24. Sun L, Wang X, Zhou Y, Ho WZ, Li JL. Exosomes Contribute to the Transmission of Anti-HIV Activity From TLR3-Activated Brain Microvascular Endothelial Cells to Macrophages. Antiviral Res (2016) 134:167-71. doi: 10.1016/j.antiviral.2016.07.013

25. Xu X, Zhang B, Guo L, Liu L, Meng FZ, Wang X, et al. Exosomes Transport Anti-Human Immunodeficiency Virus Factors From Human Cervical Epithelial Cells to Macrophages. J Innate Immun (2021) 3:1-11. doi: $10.1159 / 000514886$

26. Madison MN, Jones PH, Okeoma CM. Exosomes in Human Semen Restrict HIV-1 Transmission by Vaginal Cells and Block Intravaginal Replication of LP-BM5 Murine AIDS Virus Complex. Virology (2015) 482:189-201. doi: $10.1016 /$ j.virol.2015.03.040

27. Welch JL, Kaddour H, Schlievert PM, Stapleton JT, Okeoma CM. Semen Exosomes Promote Transcriptional Silencing of HIV-1 by Disrupting NF- $\mathrm{kb} /$ Sp1/Tat Circuitry. J Virol (2018) 92(21):e00731-18. doi: 10.1128/JVI.00731-18

28. Welch JL, Kaddour H, Winchester L, Fletcher CV, Stapleton JT, Okeoma CM. Semen Extracellular Vesicles From HIV-1-Infected Individuals Inhibit HIV-1 Replication In Vitro, and Extracellular Vesicles Carry Antiretroviral Drugs In Vivo. J Acquir Immune Defic Syndr (2020) 83(1):90-8. doi: 10.1097/ QAI.0000000000002233

29. Smith JA, Daniel R. Human Vaginal Fluid Contains Exosomes That Have an Inhibitory Effect on an Early Step of the HIV-1 Life Cycle. AIDS (2016) 30 (17):2611-6. doi: 10.1097/QAD.0000000000001236

30. Calin R, Hamimi C, Lambert-Niclot S, Carcelain G, Bellet J, Assoumou L, et al. Treatment Interruption in Chronically HIV-Infected Patients With an Ultralow HIV Reservoir. AIDS (2016) 30(5):761-9. doi: 10.1097/ QAD.0000000000000987

31. Chun TW, Davey RT, Engel D, Lane HC, Fauci AS. Re-Emergence of HIV After Stopping Therapy. Nature (1999) 401:874-5. doi: 10.1038/44755

32. Finzi D, Hermankova M, Pierson T, Carruth LM, Buck C, Chaisson RE, et al. Identification of a Reservoir for HIV-1 in Patients on Highly Active Antiretroviral Therapy. Science (1997) 278:1295. doi: 10.1126/science.278.5341.1295

33. Barton K, Winckelmann A, Palmer S. HIV-1 Reservoirs During Suppressive Therapy. Trends Microbiol (2016) 24:345-55. doi: 10.1016/j.tim.2016.01.006

34. Deeks SG. HIV: Shock and Kill. Nature (2012) 487(7408):439-40. doi: $10.1038 / 487439$ a

35. Archin NM, Kirchherr JL, Sung JA, Clutton G, Sholtis K, Xu Y, et al. Interval Dosing With the HDAC Inhibitor Vorinostat Effectively Reverses HIV Latency. J Clin Invest (2017) 127(8):3126-35. doi: 10.1172/JCI92684
36. Elliott JH, Wightman F, Solomon A, Ghneim K, Ahlers J, Cameronet MJ, et al. Activation of HIV Transcription With Short-Course Vorinostat in HIVInfected Patients on Suppressive Antiretroviral Therapy. PloS Pathog (2014) 10(10):e1004473. doi: 10.1371/journal.ppat.1004473

37. Ho Y-C, Shan L, Hosmane NN, Wang J, Laskey SB, Rosenbloom DIS, et al. Replication-Competent Non-Induced Proviruses in the Latent Reservoir Increase Barrier to HIV-1 Cure. Cell (2013) 155(3):540-51. doi: 10.1016/ j.cell.2013.09.020

38. Ait-Ammar A, Kula A, Darcis G, Verdikt R, De Wit S, Gautier V, et al. Current Status of Latency Reversing Agents Facing the Heterogeneity of HIV1 Cellular and Tissue Reservoirs. Front Microbiol (2020) 24:3060. doi: $10.3389 /$ fmicb.2019.03060

39. Pang S-W, Teow S-Y. Emerging Therapeutic Roles of Exosomes in HIV-1 Infection. Exosomes (2020) 7:147-78. doi: 10.1016/B978-0-12-8160534.00007-9

40. Raposo G, Stoorvogel W. Extracellular Vesicles: Exosomes, Microvesicles, and Friends. J Cell Biol (2013) 200(4):373-83. doi: 10.1083/jcb.201211138

41. Usami Y, Popov S, Popova E, Inoue M, Weissenhorn W, Gottlinge HG. The ESCRT Pathway and HIV-1 Budding. Biochem Soc Trans (2009) 37:181-4. doi: 10.1042/BST0370181

42. Gould SJ, Booth AM, Hildreth JE. The Trojan Exosome Hypothesis. Proc Natl Acad Sci USA (2003) 100:10592-7. doi: 10.1073/pnas.1831413100

43. Columba Cabezas S, Federico M. Sequences Within RNA Coding for HIV-1 Gag P17 Are Efficiently Targeted to Exosomes. Cell Microbiol (2013) 15:41229. doi: $10.1111 / \mathrm{cmi} .12046$

44. Narayanan A, Iordanskiy S, Das R, Van Duyne R, Santos S, Jaworski E, et al. Exosomes Derived From HIV-1-Infected Cells Contain Trans-Activation Response Element RNA. J Biol Chem (2013) 288:20014-33. doi: 10.1074/ jbc.M112.438895

45. Bernard MA, Zhao H, Yue SC, Anandaiah A, Tachado SD. Novel HIV-1 miRNAs Stimulate TNFalpha Release in Human Macrophages via TLR8 Signaling Pathway. PloS One (2014) 9:e106006. doi: 10.1371/ journal.pone.0106006

46. Sampey GC, Saifuddin M, Schwab A, Barclay R, Punya S, Chung MC, et al. Exosomes From HIV-1-Infected Cells Stimulate Production of ProInflammatory Cytokines Through Trans-Activating Response (TAR) RNA. J Biol Chem (2016) 291(3):1251-66. doi: 10.1074/jbc.M115.662171

47. Fang Y, Wu N, Gan X, Morrell JC, Gouldet SJ. Higher-Order Oligomerization Targets Plasma Membrane Proteins and HIV Gag to Exosomes. PloS Biol (2007) 5(6):e158. doi: 10.1371/journal.pbio.0050158

48. Lenassi M, Cagney G, Liao M, Vaupotic T, Bartholomeeusen K, Cheng Y, et al. HIV Nef Is Secreted in Exosomes and Triggers Apoptosis in Bystander CD4+ T Cells. Traffic (2010) 11(1):110-22. doi: 10.1111/j.1600-0854.2009.01006.x

49. de Carvalho JV, de Castro RO, da Silva EZ, Silveira PP, da Silva-Januario ME, Arruda E, et al. Nef Neutralizes the Ability of Exosomes From CD4+ T Cells to Act as Decoys During HIV-1 Infection. PloS One (2014) 9(11):e113691. doi: 10.1371/journal.pone.0113691

50. Xu W, Santini PA, Sullivan JS, He JS, Shan M, Ball SC, et al. HIV-1 Evades Virus-Specific IgG2 and IgA Responses by Targeting Systemic and Intestinal B Cells via Long-Range Intercellular Conduits. Nat Immunol (2009) 10 (9):1008-17. doi: 10.1038/ni.1753

51. Del Río-Iñiguez I, Vázquez-Chávez E, Cuche C, Bartolo VD, Bouchet J, Alcover A. HIV-1 Nef Hijacks Lck and Racl Endosomal Traffic To Dually Modulate Signaling-Mediated and Actin Cytoskeleton-Mediated T Cell Functions. J Immunol (2018) 201(9):2624-40. doi: 10.4049/jimmunol.1800372

52. Mukhamedova N, Hoang A, Dragoljevic D, Dubrovsky L, Pushkarsky T, Low $\mathrm{H}$, et al. Exosomes Containing HIV Protein Nef Reorganize Lipid Rafts Potentiating Inflammatory Response in Bystander Cells. PloS Pathog (2019) 15(7):e1007907. doi: 10.1371/journal.ppat.1007907

53. Admyre C, Johansson SM, Paulie S, Gabrielsson S. Direct Exosome Stimulation of Peripheral Human T Cells Detected by ELISPOT. Eur J Immunol (2006) 36:1772-81. doi: 10.1002/eji.200535615

54. Raposo G, Nijman HW, Stoorvogel W, Liejendekker R, Harding CV, Melief CJ, et al. B Lymphocytes Secrete Antigen-Presenting Vesicles. J Exp Med (1996) 183:1161-72. doi: 10.1084/jem.183.3.1161

55. Tang X, Lu H, Dooner M, Chapman S, Quesenberry PJ, Ramratnam B. Exosomal Tat Protein Activates Latent HIV-1 in Primary, Resting CD4+ T Lymphocytes. JCI Insight (2018) 3(7):95676. doi: 10.1172/jci.insight.95676 
56. Hong X, Schouest B, Xu H. Effects of Exosome on the Activation of CD4+ T Cells in Rhesus Macaques: A Potential Application for HIV Latency Reactivation. Sci Rep (2017) 7(1):15611. doi: 10.1038/s41598-017-15961-x

57. Chiozzini C, Arenaccio C, Olivetta E, Anticoli S, Manfredi F, Ferrantelli F, et al. Trans-Dissemination of Exosomes From HIV-1-Infected Cells Fosters Both HIV-1 Trans-Infection in Resting CD4+ T Lymphocytes and Reactivation of the HIV-1 Reservoir. Arch Virol (2017) 162(9):2565-77. doi: 10.1007/s00705-017-3391-4

58. Barclay RA, Schwab A, DeMarino C, Akpamagbo Y, Lepene B, Kassaye S, et al. Exosomes From Uninfected Cells Activate Transcription of Latent HIV-1. J Biol Chem (2017) 292(28):11682-701. doi: 10.1074/jbc.M117.793521

59. Arenaccio C, Anticoli S, Manfredi F, Chiozzini C, Olivetta E, Federico M. Latent HIV-1 Is Activated by Exosomes From Cells Infected With Either Replication-Competent or Defective HIV-1. Retrovirology (2015) 12:87. doi: 10.1186/s12977-015-0216-y

60. Arenaccio C, Chiozzini C, Columba-Cabezas S, Manfredi F, Affabris E, Baur A, et al. Exosomes From Human Immunodeficiency Virus Type 1 (HIV-1)Infected Cells License Quiescent CD4+ T Lymphocytes to Replicate HIV-1 Through a Nef- and ADAM17-Dependent Mechanism. J Virol (2014) 88 (19):11529-39. doi: 10.1128/JVI.01712-14

61. McNamara RP, Costantini LM, Myers TA, Schouest B, Maness NJ, Griffith JD, et al. Nef Secretion Into Extracellular Vesicles or Exosomes Is Conserved Across Human and Simian Immunodeficiency Viruses. mBio (2018) 9(1): e02344-17. doi: 10.1128/mBio.02344-17

62. Kadiu I, Narayanasamy P, Dash PK, Zhang W, Gendelman HE. Biochemical and Biologic Characterization of Exosomes and Microvesicles as Facilitators of HIV-1 Infection in Macrophages. J Immunol (2012) 189(2):744-54. doi: 10.4049/jimmunol.1102244

63. Arakelyan A, Fitzgerald W, Zicari S, Vanpouille C, Margolis L. Extracellular Vesicles Carry HIV Env and Facilitate Hiv Infection of Human Lymphoid Tissue. Sci Rep (2017) 7(1):1695. doi: 10.1038/s41598-017-01739-8

64. Schaefer MR, Wonderlich ER, Roeth JF, Leonard JA, Collins KL. HIV-1 Nef Targets MHC-I and CD4 for Degradation via a Final Common $\beta$-COPDependent Pathway in T Cells. PloS Pathog (2008) 4:e1000131. doi: 10.1371/ journal.ppat.1000131

65. Lubben NB, Sahlender DA, Motley AM, Lehner PJ, Benaroch P, Margaret S, et al. HIV-1 Nef-Induced Down-Regulation of MHC Class I Requires AP-1 and Clathrin But Not PACS-1 and is Impeded by AP-2. Mol Biol Cell (2007) 18:3351-65. doi: 10.1091/mbc.e07-03-0218

66. Da Silva LL, Sougrat R, Burgos PV, Janvier K, Mattera R, Bonifacino JS. Human Immunodeficiency Virus Type 1 Nef Protein Targets CD4 to the Multivesicular Body Pathway. J Virol (2009) 83:6578-90. doi: 10.1128/ JVI.00548-09

67. Wonderlich ER, Leonard JA, Collins KL. HIV Immune Evasion Disruption of Antigen Presentation by the HIV Nef Protein. Adv Virus Res (2011) 80:10327. doi: 10.1016/B978-0-12-385987-7.00005-1

68. Admyre C, Johansson SM, Rahman Qazi K, Filén JJ, Lahesmaa R, Norman M, et al. Exosomes With Immune Modulatory Features Are Present in Human Breast Milk. J Immunol (2007) 179:1969-78. doi: 10.4049/ jimmunol.179.3.1969

69. Lee JH, Schierer S, Blume K, Dindorf J, Wittki S, Xiang W, et al. HIV-Nef and ADAM17-Containing Plasma Extracellular Vesicles Induce and Correlate With Immune Pathogenesis in Chronic HIV Infection. EBioMedicine (2016) 6:103-13. doi: 10.1016/j.ebiom.2016.03.004

70. Konadu KA, Huang MB, Roth W, Armstrong W, Powell M, Villinger F, et al. Isolation of Exosomes From the Plasma of HIV-1 Positive Individuals. J Vis $\operatorname{Exp}$ (2016) 107):1-9. doi: 10.3791/53495

71. Falasca K, Lanuti P, Ucciferri C, Pieragostino D, Concetta Cufaro M, Bologna G, et al. Circulating Extracellular Vesicles as New Inflammation Marker in HIV Infection. AIDS (2021) 35(4):595-604. doi: 10.1097/QAD.0000000000002794

72. Kodidela S, Ranjit S, Sinha N, McArthur C, Kumar A, Kumar S. Cytokine Profiling of Exosomes Derived From the Plasma of HIV-Infected Alcohol Drinkers and Cigarette Smokers. PloS One (2018) 13(7):e0201144. doi: 10.1371/journal.pone.0201144

73. Ostalecki C, Wittki S, Lee JH, Geist MM, Tibroni N, Harrer T, et al. HIV Nefand Notch1-Dependent Endocytosis of ADAM17 Induces Vesicular TNF Secretion in Chronic HIV Infection. EBioMedicine (2016) 13:294-304. doi: 10.1016/j.ebiom.2016.10.027
74. Chettimada S, Lorenz DR, Misra V, Wolinsky SM, Gabuzda D. Small RNA Sequencing of Extracellular Vesicles Identifies Circulating miRNAs Related to Inflammation and Oxidative Stress in HIV Patients. BMC Immunol (2020) 21 (1):57. doi: 10.1186/s12865-020-00386-5

75. Duette G, Pereyra PP, Rubione J, Perez PS, Landay AL, Crowe SM, et al. Induction of HIF- $1 \alpha$ by HIV-1 Infection in CD4+ T Cells Promotes Viral Replication and Drives Extracellular Vesicle-Mediated Inflammation. mBio (2018) 9(5):e00757-18. doi: 10.1128/mBio.00757-18

76. Mack M, Kleinschmidt A, Bruhl H, Klier C, Nelson PJ, Cihak J, et al. Transfer of the Chemokine Receptor CCR5 Between Cells by Membrane-Derived Microparticles: A Mechanism for Cellular Human Immunodeficiency Virus 1 Infection. Nat Med (2000) 6:769-75. doi: 10.1038/77498

77. Rozmyslowicz T, Majka M, Kijowski J, Murphy SL, Conover DO, Poncz M, et al. Platelet- and Megakaryocyte-Derived Microparticles Transfer CXCR4 Receptor to CXCR4-Null Cells and Make Them Susceptible to Infection by X4-HIV. AIDS (2003) 17:33-42. doi: 10.1097/00002030-200301030-00006

78. Dean M, Carrington M, Winkler C, Huttley GA, Smith MW, Allikmets R, et al. Genetic Restriction of HIV-1 Infection and Progression to AIDS by a Deletion Allele of the CKR5 Structural Gene. Hemophilia Growth and Development Study, Multicenter AIDS Cohort Study, Multicenter Hemophilia Cohort Study, San Francisco City Cohort, ALIVE Study. Science (1996) 273(5283):1856-62. doi: 10.1126/science.273.5283.1856

79. Tumne A, Prasad VS, Chen Y, Stolz DB, Saha K, Ratner DM, et al. Noncytotoxic Suppression of Human Immunodeficiency Virus Type 1 Transcription by Exosomes Secreted From CD8+ T Cells. J Virol (2009) 83 (9):4354-64. doi: 10.1128/JVI.02629-08

80. Khatua AK, Taylor HE, Hildreth JE, Popik W, et al. Exosomes Packaging APOBEC3G Confer Human Immunodeficiency Virus Resistance to Recipient Cells. J Virol (2009) 83(2):512-21. doi: 10.1128/JVI.01658-08

81. Welch JL, Kaufman TM, Stapleton JT, Okeoma CM. Semen Exosomes Inhibit HIV Infection and HIV-Induced Proinflammatory Cytokine Production Independent of the Activation State of Primary Lymphocytes. FEBS Lett (2020) 594(4):695-709. doi: 10.1002/1873-3468.13653

82. Näslund TI, Paquin-Proulx D, Paredes PT, Valhov E, Sandberg JK, Gabrielsson S. Exosomes From Breast Milk Inhibit HIV-1 Infection of Dendritic Cells and Subsequent Viral Transfer to CD4+ T Cells. AIDS (2014) 28(2):171-80. doi: 10.1097/QAD.0000000000000159

83. Antimisiaris SG, Mourtas S, Marazioti A. Exosomes and Exosome-Inspired Vesicles for Targeted Drug Delivery. Pharmaceutics (2018) 10(4):218. doi: 10.3390/pharmaceutics10040218

84. Qiu Y, Ma J, Zeng Y. Therapeutic Potential of Anti-HIV RNA-Loaded Exosomes. BioMed Environ Sci (2018) 31(3):215-26. doi: 10.3967/bes2018.027

85. Wahlgren J, De L Karlson T, Brisslert M, Sani FV, Telemo E, Sunnerhagen P, et al. Plasma Exosomes Can Deliver Exogenous Short Interfering RNA to Monocytes and Lymphocytes. Nucleic Acids Res (2012) 40(17):e130. doi: $10.1093 / \mathrm{nar} / \mathrm{gks} 463$

86. O'Loughlin AJ, Mäger I, de Jong OG, Varela MA, Schiffelers RM, El Andaloussi S, et al. Functional Delivery of Lipid-Conjugated siRNA by Extracellular Vesicles. Mol Ther (2017) 25(7):1580-7. doi: 10.1016/ j.ymthe.2017.03.021

87. Kumar S, Zhi K, Mukherji A, Gerth K. Repurposing Antiviral Protease Inhibitors Using Extracellular Vesicles for Potential Therapy of COVID-19. Viruses (2020) 12(5):486. doi: 10.3390/v12050486

88. Pinky, Gupta S, Krishnakumar V, Sharma Y, Dinda AK, Mohanty S. Mesenchymal Stem Cell Derived Exosomes: A Nano Platform for Therapeutics and Drug Delivery in Combating COVID-19. Stem Cell Rev Rep (2021) 17(1):33-43. doi: 10.1007/s12015-020-10002-z

89. Kugeratski FG, Kalluri R. Exosomes as Mediators of Immune Regulation and Immunotherapy in Cancer. FEBS J (2021) 288(1):10-35. doi: 10.1111/ febs. 15558

90. Nanjundappa RH, Wang R, Xie Y, Umeshappa CS, Xiang J. Novel CD8+ T Cell-Based Vaccine Stimulates Gp120-Specific CTL Responses Leading to Therapeutic and Long-Term Immunity in Transgenic HLA-A2 Mice. Vaccine (2012) 30(24):3519-25. doi: 10.1016/j.vaccine.2012.03.075

91. Lattanzi L, Federico M. A Strategy of Antigen Incorporation Into Exosomes: Comparing Cross-Presentation Levels of Antigens Delivered by Engineered Exosomes and by Lentiviral Virus-Like Particles. Vaccine (2012) 30(50):722937. doi: $10.1016 /$ j.vaccine. 2012.10 .010 
92. Barclay RA, Mensah GA, Cowen M, DeMarino C, Kim Y, Pinto DO, et al. Extracellular Vesicle Activation of Latent HIV-1 Is Driven by EV-Associated C-Src and Cellular SRC-1 via the PI3K/AKT/mTOR Pathway. Viruses (2020) 12(6):665. doi: 10.3390/v12060665

93. Anyanwu SI, Doherty A, Powell MD, Obialo C, Huang MB, Quarshie A, et al. Detection of HIV-1 and Human Proteins in Urinary Extracellular Vesicles From HIV+ Patients. Adv Virol (2018) 2018:7863412. doi: 10.1155/2018/ 7863412

94. Stroud JC, Oltman A, Han A, Bates DL, Chen L. Structural Basis of HIV-1 Activation by NF-Kappab-a Higher-Order Complex of P50:RelA Bound to the HIV-1 LTR. J Mol Biol (2009) 393(1):98-112. doi: 10.1016/ j.jmb.2009.08.023

95. Duh EJ, Maury WJ, Folks TM, Fauci AS, Rabson AB. Tumor Necrosis Factor Alpha Activates Human Immunodeficiency Virus Type 1 Through Induction of Nuclear Factor Binding to the NF-Kappa B Sites in the Long Terminal Repeat. Proc Natl Acad Sci USA. (1989) 86(15):5974-8. doi: 10.1073/ pnas.86.15.5974
Conflict of Interest: The authors declare that the research was conducted in the absence of any commercial or financial relationships that could be construed as a potential conflict of interest.

Publisher's Note: All claims expressed in this article are solely those of the authors and do not necessarily represent those of their affiliated organizations, or those of the publisher, the editors and the reviewers. Any product that may be evaluated in this article, or claim that may be made by its manufacturer, is not guaranteed or endorsed by the publisher.

Copyright $\odot 2022$ Navarrete-Muñoz, Llorens, Benito and Rallón. This is an openaccess article distributed under the terms of the Creative Commons Attribution License (CC BY). The use, distribution or reproduction in other forums is permitted, provided the original author(s) and the copyright owner(s) are credited and that the original publication in this journal is cited, in accordance with accepted academic practice. No use, distribution or reproduction is permitted which does not comply with these terms. 


\section{GLOSSARY}

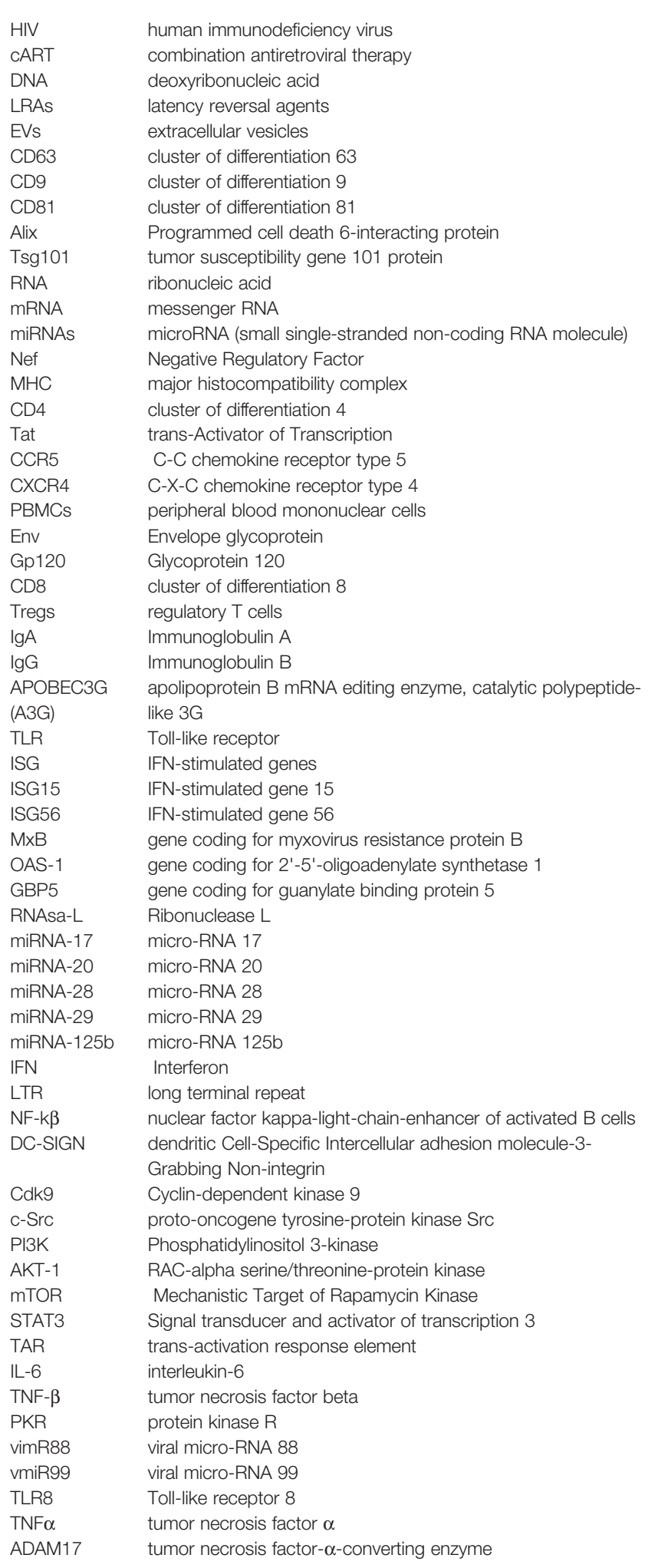

